\title{
Comparison of the B vitamin composition of milk from mothers of preterm and term babies
}

\author{
J E FORD, ALICJA ZECHALKO, J MURPHY, AND O G BROOKE
}

Nutrition Department, National Institute for Research in Dairying, Reading; Department of Child Health, University Hospital of Wales; Department of Child Health, St George's Hospital Medical School, London

SUMmARY Samples of milk were taken at intervals during lactation from 35 mothers of term and 26 mothers of preterm infants and assayed for $8 \mathrm{~B}$ complex vitamins. Both term and preterm milks varied widely in vitamin content between mothers. Mean concentrations of thiamin, vitamin $\mathbf{B}_{6}$, nicotinic acid, pantothenic acid, biotin, and folic acid increased progressively over several weeks after parturition but vitamin $\mathbf{B}_{12}$ concentrations declined generally and riboflavin values showed little change. Preterm milk was not richer in vitamins than term milk of the corresponding stage of lactation and it appeared that intake of B vitamins differed widely among preterm infants given their own mothers' milk. These infants may have meagre body reserves and an increased need for vitamins, and breast milk whether from their own mother or from the milk bank may not meet their needs. There is a strong case for supplementing breast milk given to preterm babies with the B complex vitamins.

Whether nature provides for the special nutritional needs of the preterm infant is an interesting and controversial question. Clinical studies on preterm babies given mature donor milk have yielded conflicting results, but the predominant view strongly expressed by Davies ${ }^{1}$ and by Fomon et al. ${ }^{2}$ is that mature human milk may be seriously deficient in protein and perhaps in other nutrients also.

Recent studies have shown appreciable differences in the composition of term (T) and preterm (PT) milk. During the early weeks of lactation PT milk is much richer in protein and several minerals ${ }^{3-8}$ and may be closer attuned to the nutritional needs of the preterm baby. Lemons et al. ${ }^{8}$ calculated that $170-200 \mathrm{ml} / \mathrm{kg} /$ day of 'average' PT milk would supply all the nutrients except calcium, phosphorus, and possibly iron, needed by a preterm infant of 33 weeks' gestation to sustain the intrauterine growth rate. They concluded that the milk from the baby's mother was preferable to $\mathrm{T}$ milk or pooled mature breast milk, but that supplementation with calcium, phosphorus, and possibly other factors might be warranted. Gross et al. ${ }^{4}$ stated that 'PT milk appears to approximate more closely the nutritional needs of the preterm infant than does other breast milk', but later ${ }^{5}$ they reported wide variability in the composition of PT milk from different women and warned that the nutrient con- centrations might sometimes be inadequate for the baby's needs. Hibberd et al. ${ }^{9}$ also found wide variation in the composition of PT milk. They were unconvinced of the nutritional superiority of PT milk and suggested that a higher nitrogen content resulted from 'leakage' of serum proteins into the alveoli of the immature mammary gland and was not therefore an adaptation to the needs of the preterm infant.

The question of the adequacy of milk from surrogate mothers and indeed of the maternal milk as sources of vitamins for the rapidly growing preterm infant has so far received little attention. There is as yet no published report comparing the vitamin composition of $T$ and PT milk and the present study was undertaken to provide data on the B vitamin content of such milk.

\section{Materials and methods}

Milk samples. Milk samples were obtained from the Human Milk Bureau, St David's Hospital, Cardiff; the Dunn Nutritional Laboratory, Cambridge; the Department of Paediatrics, John Radcliffe Hospital, Oxford; and the Department of Child Health, St George's Hospital Medical School, London. PT milk was from 26 mothers of babies of 29-34 weeks' gestation and $\mathrm{T}$ milk from 35 mothers of babies delivered at 39 weeks or later. Twenty four hour collections were made from 2 of the preterm mothers, 
on days $6,9,15,22,29$, and 36 postpartum and subsamples taken for analysis.

Most of the remaining PT milk samples were not from 24 hour collections, but were taken from 1 breast only, usually between 8 and $10 \mathrm{am}$. The milk was expressed as completely as possible using an electric pump and a sample was taken for analysis. Samples were obtained at intervals between 1 and 49 days postpartum, and further samples covering the period 7 to 28 weeks were provided by 3 of the mothers. This sampling procedure was not perfect but the number of samples contributing to each mean value (19-48) was large enough to minimise any likely effects of random diurnal variation on vitamin content. For this study, no greater interference in the feeding routine was needed to support our conclusions.

The T milks were composites of samples expressed manually over the day during the baby's feeding times. Mature T milk samples were from 23 mothers in Cambridge who were 67-250 days postpartum, though 2 (sometimes 3) samples taken at other collection centres at about 17 days were also included. Each of the Cambridge samples was a composite made up of milk taken in mid feed at 4 different times spread over the day on 4 successive days. All the milk samples were stored at $-20^{\circ}$ for analysis.

Vitamin assays. Riboflavin, nicotinic acid, pantothenic acid, and biotin were assayed by standard microbiological methods. ${ }^{10}{ }^{11}$ Folate was measured with Lactobacillus casei by an adaptation of the procedure described by Herbert ${ }^{12}$ for the assay of folate in blood serum. ${ }^{13}$ Vitamin $B_{12}$ was assayed with $L$ leichmannii as described by Gregory. ${ }^{14}$ Thiamin was assayed with $L$ ferment $i$; the test medium was that of Banhidi ${ }^{15}$ and the milk samples $(1 \mathrm{ml})$ were extracted by heating for $30 \mathrm{~min}$ at $100^{\circ}$ with $20 \mathrm{ml} 0.033 \mathrm{M}$ sulphuric acid. Vitamin $\mathbf{B}_{6}$ was assayed with Kloeckera brevis as described by Barton-Wright ${ }^{16}$ except that the test samples were extracted with $0.055 \mathrm{M}$ hydrochloric acid as recommended by Gregory. ${ }^{17}$

The vitamins were assayed once only in the main, and in several instances there was insufficient test sample for the full range of assays. The assays were interpolated in a larger series of assays on milk in which reference milk samples were included and assayed repeatedly as a check on within assay and between assay variability. From this experience it was apparent that errors of measurement made a small contribution only to the comparatively wide ranges of variation given with the mean values in Tables 1 and 2. A standard deviation of about $3 \%$ would be fairly representative for all of the assays.

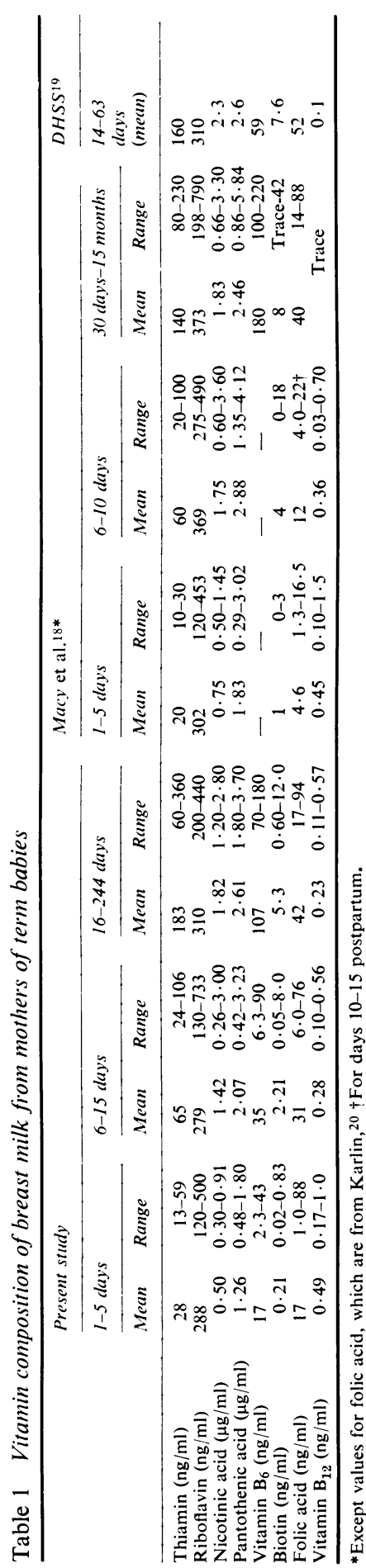


Table 2 Vitamin content of term $(T)$ and preterm $(P T)$ breast milk

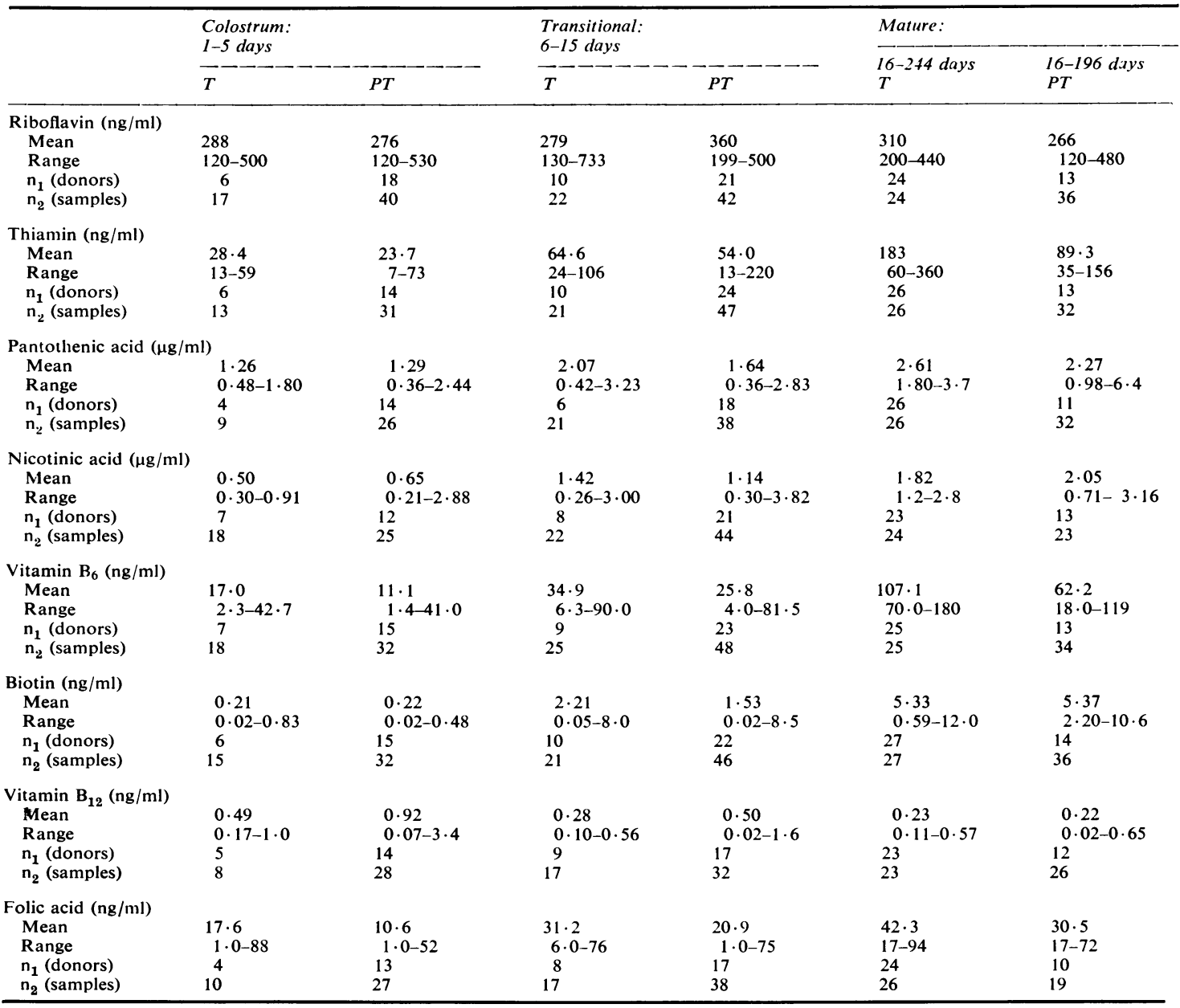

\section{Results}

Vitamin composition of term milk. Macy et al. ${ }^{18}$ published critical and comprehensive data on the chemical composition of $\mathbf{T}$ milk-mostly pooled 24 hour collections obtained from about 200 women. Table 1 lists their values for $7 \mathrm{~B}$ complex vitamins together with those found in the present study and with values for pooled mature human milk given by the Department of Health and Social Security (DHSS). ${ }^{19}$ It has become evident that values given by Macy et al. ${ }^{18}$ for folic acid were incorrect and in Table 1 these are replaced by more acceptable values taken from a detailed study by Karlin. ${ }^{20}$

If mean values are compared there is a close similarity between our results and those of Macy et al. ${ }^{18}$ Both show a wide normal range of variation in vitamin content. Mean concentrations of thiamin, vitamin $\mathbf{B}_{6}$, nicotinic acid, pantothenic acid, biotin, and folic acid increased progressively with duration of lactation. Riboflavin also increased, but to a lesser extent. In contrast, vitamin $\mathrm{B}_{12}$ concentrations fell.

Our mean value for vitamin $\mathbf{B}_{6}$ in mature milk was $107 \mathrm{ng} / \mathrm{ml}$, while Macy et al. reported 180 $\mathrm{ng} / \mathrm{ml} .{ }^{18}$ Our mean value may represent a selection of less mature milk samples including as it does samples taken over 16-244 (mean 87) days postpartum, as against 30 days -15 months (mean not given) of Macy et al. Certainly this explanation must account for the even lower value $(59 \mathrm{ng} / \mathrm{ml})$ given by the DHSS ${ }^{19}$ for mature milk taken 14-63 (mean 36) days after parturition. Macy ${ }^{21}$ held that mature milk does not flow until 4-6 weeks after parturition. 
The DHSS ${ }^{19}$ report gives the same value $(0 \cdot 1$ $\mathrm{ng} / \mathrm{ml}$ ) for vitamin $B_{12}$ in mature milk from 5 collection centres. This uniformity is surprising, and the results should perhaps be regarded with caution since Gregory ${ }^{14}$ found that vitamin $B_{12}$ in human milk was not released by the extraction procedure that was used for these analyses. Our values were higher, in the range $0 \cdot 11-0.57$ (mean $0 \cdot 23) \mathrm{ng} / \mathrm{mll}$.

Vitamin composition of term and preterm milk. Table 2 compares the B vitamin composition of colostrum, transitional milk, and mature milk from mothers of term and preterm babies. Mean values and ranges are given. In several instances, and especially with colostrum and transitional milk, the distribution of the values was not normal and it was decided that the standard deviations gave no useful information and were better omitted. Mean riboflavin concentrations were similar in T and PT milk and showed no appreciable change with advancing lactation. Thiamin content increased greatly with duration of lactation-apparently more so with $\mathrm{T}$ than with PT milk. The mean content in mature PT milk $(89 \mathrm{ng} / \mathrm{ml})$ was only half of that in the T milk $(183 \mathrm{ng} / \mathrm{ml})$ and much lower than the value (169 $\mathrm{ng} / \mathrm{ml}$ ) given by the DHSS ${ }^{19}$ as representing mature $T$ milk at about 36 days' postpartum.

Vitamin $\mathbf{B}_{6}$ and folic acid followed a similar pattern to thiamin, though with these 2 vitamins it seems likely that the lower content in the mature PT milk may be attributable to the relative immaturity of the milk (mean $55 \mathrm{v} 87$ days postpartum respectively). Our value of $62 \mathrm{ng} / \mathrm{ml}$ for vitamin B $_{6}$ in PT milk at about 55 days may be compared with $59 \mathrm{ng} / \mathrm{ml}$ for $\mathrm{T}$ milk at about 36 days, ${ }^{19}$ and $107 \mathrm{ng} / \mathrm{ml}$ (this study) with $180 \mathrm{ng} / \mathrm{ml}^{18}$ for T milk in later lactation. $\mathrm{Karlin}^{20}$ found that the content of folic acid increased only slowly during lactation to a stable value of about $40 \mathrm{ng} / \mathrm{ml}$ by the fourth month.

The content of pantothenic acid increased from about $1.2 \mu \mathrm{g} / \mathrm{ml}$ in colostrum to $2.6 \mu \mathrm{g} / \mathrm{ml}$ in mature $\mathrm{T}$ milk. The mean values were lower in PT milk but the differences were not significant. Nicotinic acid and biotin concentrations increased similarly with duration of lactation, and again the mean values were much the same in T and PT milk. Mean vitamin $B_{12}$ concentrations were highest in colostrum and higher in PT than $T$ milk. The content fell with duration of lactation and in mature lactation the mean concentration was the same in PT and T milk.

Individual variation. Each mean in Tables 1 and 2 represents a wide range of values. In several instances the variation reflects systematic differences between milks from different mothers. The figure
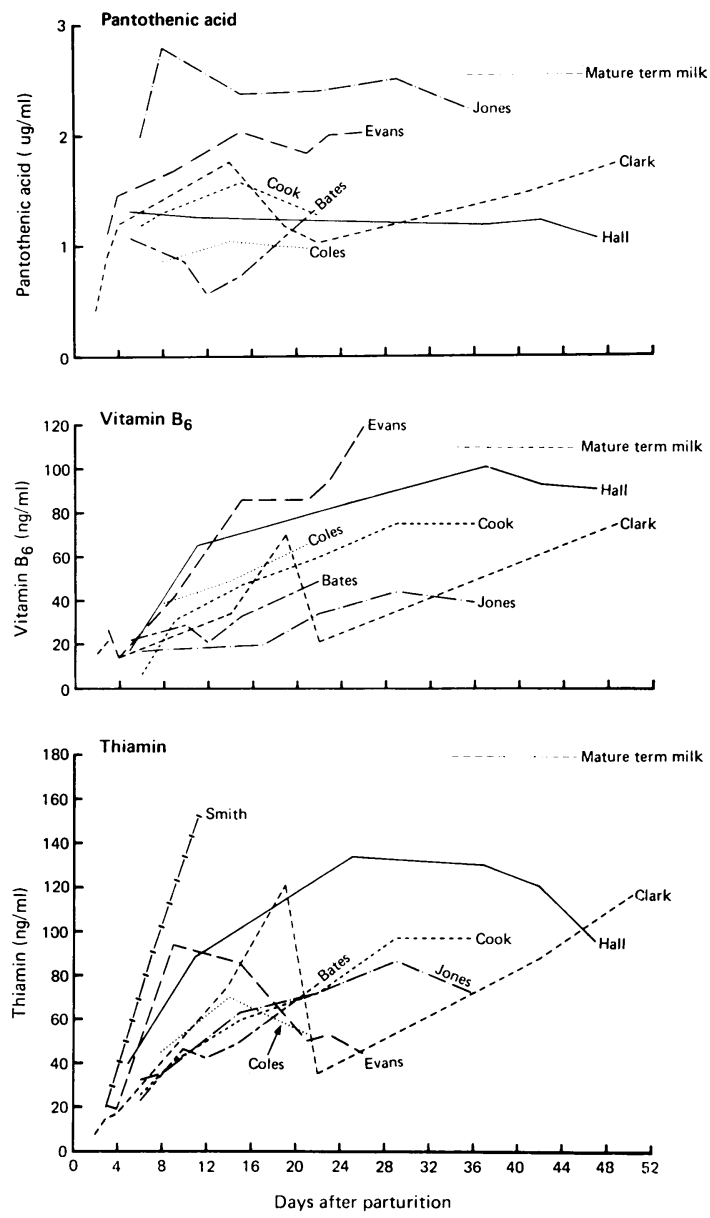

Figure Vitamin concentrations in preterm milk. Content of pantothenic acid, vitamin $B_{6}$, and thiamin in milk from several mothers taken at intervals during the early weeks of lactation.

shows values for pantothenic acid, vitamin $B_{6}$, and thiamin in serial samples from several of the preterm mothers during the early weeks of lactation. There were large differences in pantothenic acid concentrations in milks from the different mothers, and at 7 weeks the values for 'Mrs Hall' and 'Mrs Clark' were still low. Similarly, vitamin $\mathbf{B}_{6}$ and thiamin concentrations were lower than in mature $\mathrm{T}$ milk and there were consistent differences between mothers.

Folic acid and biotin concentrations increased slowly with duration of lactation and there was wide variation between milks from different mothers. With vitamin $B_{12}$ there was no such consistent 
pattern. The general trend was for the content to decline but in 1 instance the values increased sharply. In 1 mother, a vegetarian, the milk samples were uniformly low in vitamin $B_{12}(0.02 \mathrm{ng} / \mathrm{ml})$.

Among preterm babies given their own mothers' milk, intake of B vitamins may differ widely and systematically for several weeks after parturition. 'Baby Hall', for example (Figure), during his first 7 weeks received milk that contained only $1.2 \mu \mathrm{g}$ pantothenic acid per $\mathrm{ml}$, whereas 'baby Jones' received about $2.4 \mu \mathrm{g} / \mathrm{ml}$. Conversely, with vitamin $\mathbf{B}_{6}$, 'baby Jones' received considerably less than 'baby Hall'.

\section{Discussion}

Pooled banked milk is often given to preterm babies, though it does not provide sufficient nutrients to sustain the intrauterine growth rate, or as rapid growth as with a cows' milk formula. ${ }^{22}{ }^{23}$ There has been little speculation about the adequacy of the vitamin content, though we may reasonably suppose that the vitamin needs of the faster growing PT baby are proportionately greater than those of the $T$ baby, while a smaller volume of milk can be tolerated by the tiny infant. This study examined whether the mother's own milk is a better source of vitamins than other milk. The results show that PT milk is not richer in any of the vitamins than $T$ milk of the corresponding stage of lactation, and that it is poorer in thiamin and possibly also in folate and vitamin $\mathbf{B}_{6}$.

The wide variation in composition of milks from different women is an important consideration which should be taken into account before mothers of preterm babies are encouraged to express milk for feeding to their babies. Macy and Kelly ${ }^{24}$ pointed out that 'some women secrete a milk persistently low or high in one or more nutrients' and Gross et $a l .5$ warned that 'the wide range of nutrient concentrations of milk from different women ... makes invalid the assumption that all feedings of expressed milk contain adequate nutrient concentrations for the preterm baby'. This variation is particularly pronounced in the vitamin composition.

It may be supposed that these differences are of no great nutritional consequence since the wide variation in vitamin content among $T$ milks is regarded as normal. But it would be imprudent to assume that this is the case. There is need for better knowledge of the vitamin reserves of newborn PT and $T$ babies and of their relative and comparative requirement for vitamins. To give unsupplemented breast milk from the mother or the milk bank to a preterm infant with inadequate body stores could result in further depletion of the reserves and make the baby's vitamin nutritional status even more precarious. There is for example, a much higher incidence and earlier onset of megaloblastic anaemia of folate deficiency in PT than in T infants. ${ }^{25} 26$ Term infants have higher red cell folate concentrations, indicating a rapid placental transfer of folate during the final weeks of pregnancy ${ }^{27}$ and this is reflected in a higher incidence of megaloblastic anaemia in mothers during the last few weeks of gestation and early puerperium. ${ }^{28}$ It may well be that this is the same for other vitamins. Many small preterm infants have been electively delivered because of poor intrauterine growth and failing placental function and these babies in particular may be expected to have low vitamin reserves.

It is common practice among neonatal paediatricians to give supplementary vitamins to preterm infants; a widely used multivitamin supplement (Abidec; Parke Davis) contains thiamin, riboflavin, pyridoxine, nicotinamide, and vitamins $A, C$, and D. Folic acid and vitamin $E$ are also given frequently, but not pantothenic acid, biotin, and vitamin $B_{12}$. There is a strong case for giving preterm babies a comprehensive supplement containing all the $\mathrm{B}$ complex vitamins with breast milk, whether it is the mother's own milk or pooled donor milk.

We thank Dr Alison Paul and Dr A Williams for generous help in obtaining milk samples, and Dinah Bishop and Paula Benham for technical assistance.

\section{References}

1 Davies D P. The suitability of expressed breast milk for pre-term infants. Curr Med Res Opin 1976; 4: Supplement 1, 73-84.

2 Fomon S J, Ziegler E E, Vazques H D. Human milk and the small premature infant. Am J Dis Child 1977; 131: 463-7.

3 Atkinson S A, Bryan M H, Anderson G H. Human milk: difference in nitrogen concentration in milk from mothers of term and premature infants. $J$ Pediatr 1978; 93: 67-9.

4 Gross S J, David R J, Bauman L S, Tomarelli R M. Nutritional composition of milk produced by mothers delivering preterm. $J$ Pediatr 1980; 96: 641-4.

5 Gross S J, Geller J, Tomarelli R M. Composition of breast milk from mothers of preterm infants. Pediatrics $1981 ; 68: 490-3$.

- Hibberd C M, Brooke O G, Brown I R F, Carter N D, Wood C A. Letter: Is preterm milk nutritionally advantageous? Am J Clin Nutr 1981 ; 34: 154-5.

7 Schanler R J, Oh W. Composition of breast milk obtained from mothers of premature infants compared to breast milk obtained from donors. $J$ Pediatr 1980; 96: 679-81.

${ }^{8}$ Lemons J A, Moye L, Hall D, Simmons M. Differences in the composition of preterm and term human milk during early lactation. Pediatr Res 1982; 16: 113-7.

9 Hibberd C, Brooke O G, Carter N D, Wood C. A comparison of protein concentrations and energy in breast milk from preterm and term mothers. J Hum Nutr $1982 ; 35$ : 189-98. 
10 Ford J E, Gregory M E, Porter J W G, Thompson S Y. Vitamin assay in milk and milk products by chemical and microbiological methods. Proc XIII Int Dairy Congr $1953 ; 3$ : 1282.

11 Chapman H R, Ford J E, Kon S K, et al. Further studies of the effect of processing on some vitamins of the $B$ complex in milk. J Dairy Res 1957; 24 : 191-7.

12 Herbert V. The assay and nature of folic acid activity in human serum. $J$ Clin Invest 1961; 40: 81-91.

13 Ford J E. The influence of the dissolved oxygen in milk on the stability of some vitamins towards heating and during subsequent exposure to sunlight. J Dairy Res 1967; 34: 239-47.

14 Gregory M E. The microbiological assay of vitamin $B_{12}$ in the milk of different animal species. Br J Nutr 1954; 8: 340-7.

15 Banhidi Z. Some aspects of the nutrition of Lactobacillus fermenti 36 in the tube assay of thiamine. Acta Chem Scand $[B]$ 1958; 12: 517-27.

16 Barton-Wright E C. Practical methods for the microbiological assay of the vitamin $B$ complex and amino acids. London: United Trade Press, 1963: 27-8.

17 Gregory M E. The effect of heat on the vitamin $B_{6}$ of milk. J Dairy Res 1959; 26: 203-14.

18 Macy I G, Kelly H J, Sloan R E. The composition of milks. National Research Council Publication No 254. Washington DC: National Academy of Sciences: 1950.

19 Department of Health and Social Security. The composition of mature human milk. Report on Health and Social Subjects No 12. London: HMSO, 1977: 17.

20 Karlin R. Folic acid levels in human and cows' milk. Int Z Vitam Ernahrungsforschung [Beih] 1967; 37: 334-42.
21 Macy I G. Composition of human colostrum and milk. Am J Dis Child 1949; 78: 589-603.

22 Davies D P. Adequacy of expressed breast milk for early growth of preterm infants. Arch Dis Child 1977; 52: 296-301.

23 Räihä N C F, Heinonen K, Rassin D K, Gaull G E. Milk protein quantity and quality in low birthweight infants. I. Metabolic responses and effects on growth. Pediatrics 1976; 57: 659-74.

24 Macy I G, Kelly H J. Human milk and cows' milk in infant nutrition. In: Milk: the mammary gland and its secretion. Vol. 2 edited by Kon S K, Cowie A T, eds. Academic Press, 1961 : 293.

25 Zuelzer W W, Ogden F N. Megaloblastic anemia in infancy. Am J Dis Child 1946; 71 : 211-43.

${ }^{26}$ Strelling M K, Blackledge G D, Goodall H B, Walker C H M. Megaloblastic anaemia and whole-blood folate levels in premature infants. Lancet $1966 ; 1$ : 898-900.

27 Ek J. Plasma and red cell folate values in newborn infants and their mothers in relation to gestational age. J Pediatr 1980; 97: 288-92.

28 Ainley N J. Megaloblastic anaemia of pregnancy and the puerperium. J Obstet Gynaecol Br Commonw 1961; 68: 254-60.

Correspondence to Dr J E Ford, National Institute for Research in Dairying, Shinfield, Reading RG2 9AT.

Received 2 February 1983

\section{Twenty five years ago}

\section{Proceedings of the British Paediatric Association, 1958}

On the medical care of the adolescent the British Paediatric Association did not lay down an age limit but defined adolescence as a phase of intellectual, social, educational, and physical change through which the individual progresses in passing from childhood to maturity, comprising therefore not only children in their final school years but also young workers in their early years of employment. The BPA emphasised the need for separate adolescent wards in children's hospitals and departments as soon as more accommodation became available, suggesting that some paediatricians and physicians interested in the care of the adolescent should also set aside special outpatient periods. Inpatient facilities were urgently needed for psychotic adolescents, as was confirmed 6 years later by a Ministry of Health Survey (1964) which regretted the unsuitable use of mental hospitals for more than 6000 adolescents. The hospital authorities failed to increase their provision for adolescents, possibly because, in the past, the mentally ill adolescent had not known how to complain. 'Now he has emerged as a figure in our cultural midst and is perhaps being slowly recognised.'

Neale, V. The British Paediatric Association 1952-1968. London: Pitman, 1970: 23-4. 